\title{
Population increase of Gyrodactylus derjavini on rainbow trout induced by testosterone treatment of the host
}

\author{
Kurt Buchmann* \\ Department of Veterinary Microbiology, Section of Fish Diseases, Royal Veterinary and Agricultural University, \\ 13 Bülowsvej, DK-1870 Frederiksberg C., Denmark
}

\begin{abstract}
Field observations indicating a possible effect of testosterone on the susceptibility of teleosts to gyrodactylid infections were tested experimentally. Female rainbow trout Oncorhynchus mykiss $(0+)$ were injected with testosterone $(5 \mathrm{or} 10 \mu \mathrm{g})$ or vehicle alone (placebo) and subjected to infection with Gyrodactylus derjavini Mikailov, 1975 through cohabitation with infected fish. The number of parasites on testosterone-treated fish increased significantly compared to parasites on untreated fish. The site selection of parasites differed slightly between experimental groups. Infected trout used for cohabitation experienced a marked decrease in infection, indicating acquired resistance. This was further supported by the different site selection of parasites on these fishes. The superficial mucous cell density on the tail fins of testosterone-treated fish was not significantly lower than in the placebo trout, whereas previously infected fish with a low parasite burden showed a significantly higher mucous cell density. A possible immunosuppressive effect of testosterone is discussed, but although testosterone is likely to act on the trout immune system, the possibility that the male sex hormone affects the parasites' reproduction directly cannot be excluded.
\end{abstract}

KEY WORDS: Rainbow trout - Gyrodactylus derjavini - Testosterone - Mucous cell · Host response

\section{INTRODUCTION}

Several field studies have indicated that sexually mature male teleosts are more susceptible to infection with gyrodactylids than their female counterparts. Thus, a number of ectoparasites, including GyrodactyIus sp., were recorded in higher intensities on the skin of male brown trout Salmo trutta compared to females (Pickering \& Christie 1980). In addition, precocious male salmon Salmo salar were found to harbour remarkably higher burdens of $G$. salaris than younger salmon (Malmberg \& Malmberg 1993, Appleby \& Mo 1996). Recently, Appleby (1996) recorded significantly higher infections with an unidentified Gyrodactylus species on male sand gobies Pomatoschistus minutus compared to female hosts during the breeding season.

•E-mail: kurt.buchmann@vetmi.kvl.dk
These field observations strongly suggest that male sex hormones affect the susceptibility of the teleost host to gyrodactylid infection. However, no experimental evidence has so far been presented to support or refute these observations. Similarly, as Pickering (1977) described a decline in mucous cell concentrations in the epidermis of spawning male trout, this parameter has been suggested to influence host resistance to infection with external parasites. Further evidence of a protective role of high mucous cell densities in salmonids against $G$. derjavini infections was presented by Buchmann \& Uldal (1997) and Buchmann \& Bresciani (1997). Therefore, the present investigation was undertaken to elucidate whether testosterone levels in rainbow trout Oncorhynchus mykiss are associated with population densities of $G$. derjavini on the host. In addition, the study examined whether testosterone treatment and acquired resistance to infection were related to any change of mucous cell density. 


\section{MATERIALS AND METHODS}

Fish. Female 0+ rainbow trout $(8.5$ to $9.8 \mathrm{~cm}$ total body length, 7.1 to $7.9 \mathrm{~g}$ total body weight) were obtained from a parasite-free hatchery (Siglund Fish Production, Møn, Denmark) and transported to the laboratory in oxygenated hatchery water. Fish were acclimatized in the system (temperature 11 to $12^{\circ} \mathrm{C}$ ) for 5 wk before experiments started. Female hosts were chosen to minimize the variation of the natural testosterone level.

Laboratory fish tanks. Rainbow trout were kept in two $200 \mathrm{l}$ volume glass aquaria containing $100 \mathrm{l}$ tap water. Water quality monitoring, internal recirculation, water exchange and aeration were performed as described previously (Buchmann \& Uldal 1997).

Experimental design. One aquarium contained 14 trout injected with $10 \mu \mathrm{g}$ testosterone each, 12 placeboinjected fish and 9 infected donor fish (see below). The other tank contained 14 trout injected with $5 \mu \mathrm{g}$ testosterone each, 11 placebo-injected fish and 10 donor fish. Thus, both untreated, treated and donor fish were subjected to the same infection pressure and the same water quality. The infection level was then recorded in all fish groups in the 2 aquaria for a total of $6 \mathrm{wk}$.

Temperature. The aquaria were located in a thermostat-regulated room with uniform temperature (11 to $12^{\circ} \mathrm{C}$ ).

Light. The cold room was illuminated by artificial light, applying a $12 \mathrm{~h}$ light:12 h dark cycle.

Feed. In order to secure water quality and to prevent excessive metabolic activity of the host the fish were fed a restricted diet ( $3 \%$ of the fish biomass a week) of commercial pelleted trout feed (Dana Feed A/S, Denmark).

Parasites. The rainbow trout were infected with a laboratory strain of Gyrodactylus derjavini Mikailov, 1975 originally isolated from a Danish trout farm (Paelebro Dambrug) in May 1996.

Infection method. Uninfected fish were exposed to parasites by cohabitation. Rainbow trout with a well-characterized experimental $6 \mathrm{wk}$ old infection (donor fish) were introduced into aquaria with previously uninfected trout (recipient fish). The donor fish used harboured infections from 23 to 251 parasites per fish at the start of the experiment. In this way a total of 1274 and 1279 parasites, respectively, were introduced into the 2 experimental aquaria. During the following $2 \mathrm{wk}$ all fish became infected.

Tagging of fish. To differentiate between experimental groups in the same aquarium donor fish had their adipose fin cut, the testosterone fish were marked subcutaneously with $20 \mu \mathrm{l}$ of Alcian Blue (saturated solution in distilled water) on the right dorsal flank and the placebo fish were marked correspondingly on the left dorsal flank.

Parasite counting. Following infection the fish were scrutinized weekly using a dissecting microscope with sub-illumination ( 7 to $40 \times$ magnification). Prior to examination fish were anaesthetized in methane tricaine sulfonate (MS 222) (80 $\mathrm{mg} \mathrm{l}^{-1}$ ). The location of parasites on the host fins and body structures was recorded according to Buchmann \& Bresciani (1997). In brief, the numbers of parasites on the tail fin, adipose fin, dorsal fin, pectoral fins, pelvic fins, anal fin, corpus surface, head and the corneal surface were registered on individual anaesthetized trout. No movement of parasites to a different site due to the anaesthetic was seen in this or previous investigations.

Hormones and placebo. Hormone-treated rainbow trout were injected intraperitoneally with either $10 \mu \mathrm{g}$ (experimental group 1) or $5 \mu \mathrm{g}$ (group 2) of the synthetic androgen testosterone propionate $\left(100 \mu \mathrm{g} \mathrm{ml}^{-1}\right)$ in a vehicle composed of peanut oil and benzyl alcohol (50 $\mathrm{mg} \mathrm{ml}^{-1}$ ). The vehicle alone was administered to controls (placebo).

Mucous cell counts. Following lethal anaesthesia (200 $\mathrm{mg} \mathrm{l}^{-1}$ MS 222 for $7 \mathrm{~min}$ ) tail fins were cut from uninfected fish before the experiment and from experimental fish in Week 6 and fixed in $10 \%$ neutral formalin. After $4 \mathrm{~d}$ fin material was rinsed in distilled water, stained in Alcian Blue (1\%) in acetic acid (3\%), rinsed in distilled water and finally mounted on slides in Aquamount and covered with a cover-slip. The total number of superficial mucous cells per field $\left(0.61 \mathrm{~mm}^{2}\right)$

Table 1. Gyrodactylus derjavini infecting Oncorhynchus mykiss. Mean intensity (SD) of infection in experimental groups during the $6 \mathrm{wk}$ period of investigation. "Significantly different from placebo group, $p<0.05$. ' Significantly different from initial infection level in donor fish, $p<0.05$

\begin{tabular}{|lcccccc|}
\hline & Week 1 & Week 2 & Week 3 & Week 4 & Week 5 & Week 6 \\
\hline Testosterone & 0 & 2.9 & 17.7 & $43.3 \cdot$ & 90.1 & 155.2 \\
$5 \mu \mathrm{g}$ & $(0.0)$ & $(4.1)$ & $(16.2)$ & $(21.8)$ & $(45.6)$ & $(52.2)$ \\
Placebo & 0 & 3.0 & 15 & 32.7 & 69.4 & 115.0 \\
$5 \mu \mathrm{g}$ & $(0.0)$ & $(0.8)$ & $(3.7)$ & $(11.1)$ & $(19.8)$ & $(57.5)$ \\
Donor fish & 127.4 & $52.2 \cdots$ & $53.8 \cdots$ & $50.5 \cdots$ & $39.0^{\circ}$ & $25.5 \cdots$ \\
$5 \mu \mathrm{g}$ & $(67.8)$ & $(24.1)$ & $(17.7)$ & $(15.2)$ & $(11.3)$ & $(11.3)$ \\
Testosterone & 0 & 4.2 & $36.0 \cdot$ & $95.3 \cdot$ & 224.4 & 324.2 \\
$10 \mu g$ & $(0.0)$ & $(2.8)$ & $(8.4)$ & $(17.9)$ & $(74.1)$ & $(70.3)$ \\
Placebo & 0 & 5.4 & 26.6 & 68.3 & 183.8 & 250.7 \\
$10 \mu g$ & $(0.0)$ & $(3.9)$ & $(10.8)$ & $(17.7)$ & $(45.3)$ & $(127.3)$ \\
Donor fish & 142.1 & 130.4 & 121.3 & $79.2 \cdots$ & $79.5 \cdots$ & $69.8 \cdots$ \\
$10 \mu g$ & $(86.7)$ & $(97.4)$ & $(97.5)$ & $(89.5)$ & $(106.4)$ & $(105.6)$ \\
\hline
\end{tabular}


were then counted in a compound microscope (200x magnification) using a gridded ocular. The 3 outermost fields in the mid fin were counted.

Calculations and statistics. The mean intensity of infection in the experimental groups was calculated according to Margolis et al. (1982). For every sample the proportion $(\%)$ of the total parasite population located in a particular site on the fish was calculated to reveal any change of site predilection in the different groups during the investigation. Student's $t$-test was conducted to detect differences of means. These were accepted as significant at a probability level of 0.05 .

\section{RESULTS}

\section{Infection level}

During the first week of cohabitation testosteronetreated and untreated fish were infected to the same extent with no difference in mean intensity. However, over the next 4 wk hormone-treated rainbow trout experienced a markedly higher buildup of infection compared to placebo fish with significant differences in Weeks 3 and $4(10 \mu \mathrm{g}$ testosterone group) and Week 4 (5 $\mu$ g testosterone group) (Table 1). The donor fish with a well-characterized previous infection exhibited in both aquaria a significant reduction of their parasite burden during the same period.

\section{Differences in site selection}

No differences between site selection of the 2 hormone-treated groups were detected and they were pooled when compared to the placebo groups for this parameter. Initially, all groups harboured the highest number of parasites on the pectoral fins, the tail fin, the pelvic fin and the body proper (Fig. 1). In the first 3 wk hormone-treated fish differed from placebo fish in that they carried a larger number of gyrodactylids on the body. Placebo fish, in contrast, showed more parasites on the pelvic fins. In both these groups the pectoral fins carried almost half of the parasites at 1 wk post-infection (Week 2). This proportion decreased markedly during the next $6 \mathrm{wk}$ in all groups

Fig. 1. Site selection of Gyrodactylus derjavini on rainbow trout under different experimental conditions: (a) testosterone-treated fish; (b) placebo-treated fish; (c) donor fish. Significantly fewer parasites were found on the pectoral fins of untreated fish compared to hormone treated fish in Week $6(\mathrm{p}<0.05)$
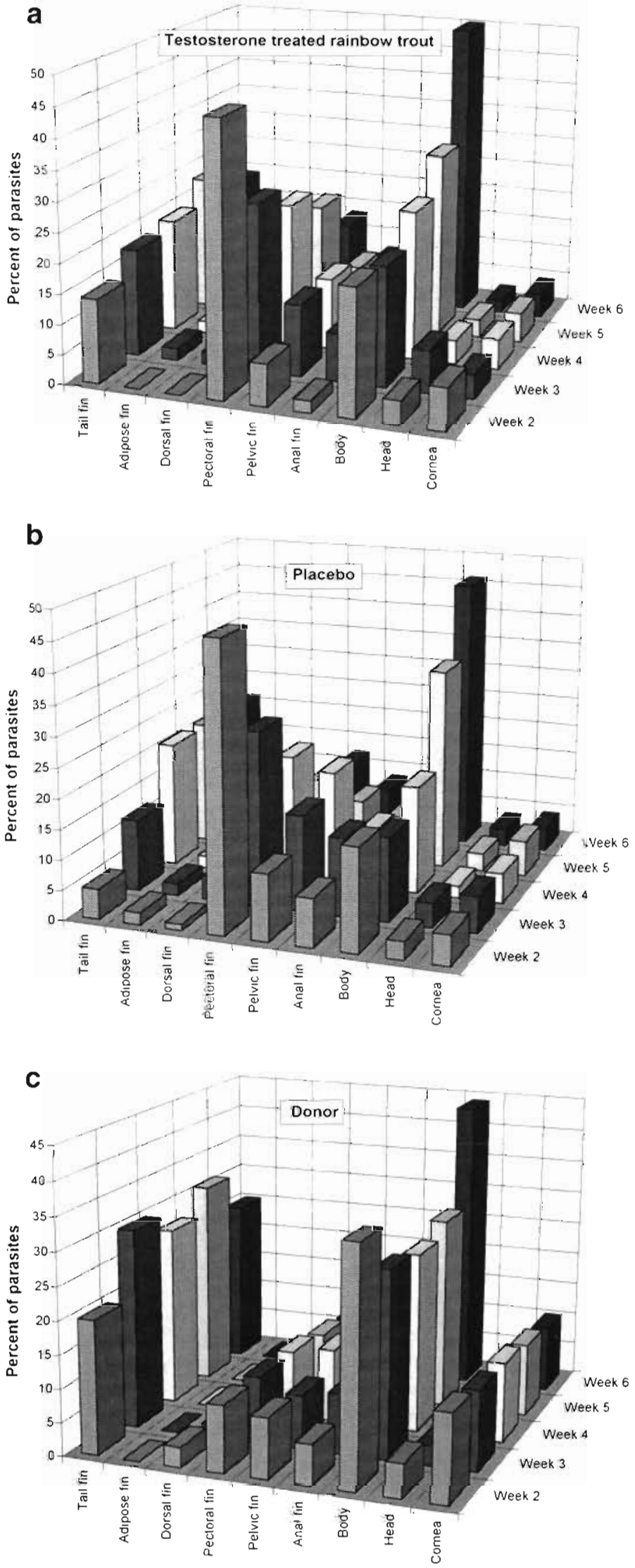
but significantly more in untreated fish (Fig. 1a, b). The corneal surface became infected but no differences between hormone and placebo groups were detected. In contrast, a clear difference in site selection between previously infected and primary infected fish was evident throughout the period of investigation. The proportion of parasites located on the corneal surface was significantly higher in primed fish (donors) compared to unprimed (testosterone and placebo) fish. In addition, the pectoral fins in donor fish harboured a significantly lower proportion of the parasites and throughout the period of investigation the body proper and the tail were preferred parasite zones (Fig. 1c). However, it should be noted that, due to the large surface area of the body, the parasite density in this body part was low.

\section{Mucous cell counts}

No differences in mucous cell densities between testosterone-treated and untreated trout were detected at any time but both groups exhibited lower counts than the uninfected fish. In contrast, the donor fish showed a significantly increased mucous cell density in the tail fin (Table 2). Some of these cells appeared morphologically different, exhibiting smaller diameters and in some areas patchy localization.

\section{DISCUSSION}

The present study has confirmed that testosterone injection of rainbow trout positively affects the population buildup of the ectoparasitic monogeneans Gyrodactylus derjavini on the skin of the host. Although much variation in abundance was present and made the differences non-significant in the last $2 \mathrm{wk}$ of

Table 2. Oncorhynchus mykiss. Mucous cell density of the 3 outermost zones in the tail fins from (1) untreated and uninfected rainbow trout, from (2) trout injected with $10 \mathrm{\mu g}$ testosterone and infected, from (3) placebo trout (infected) and from (4) donor fish after relative recovery from infection (Week 6). -Significantly different from testosterone and placebo fish, $p<0.05$

\begin{tabular}{|lcccc|}
\hline & Untreated & $\begin{array}{c}\text { Testost.- } \\
\text { treated }\end{array}$ & Placebo & $\begin{array}{c}\text { Donor } \\
\text { fish }\end{array}$ \\
\hline $\begin{array}{l}\text { No. of zones } \\
\text { counted }\end{array}$ & 30 & 27 & 27 & 30 \\
$\begin{array}{l}\text { Mean no. of } \\
\text { mucous cells zone }\end{array}$ & $111.7^{-1}$ & 71.3 & 70.1 & $169.3^{\cdot}$ \\
$\mathrm{SD}$ & 40.5 & 32.3 & 20.9 & 69.8 \\
\hline
\end{tabular}

investigation, a general trend towards a higher abundance in hormone-treated hosts was evident. At least 2 mechanisms can be suggested to explain this effect, i.e. both an immunosuppressive effect on the host induced by testosterone and a direct reproductionenhancing effect of the sex hormone on the parasites can be hypothesized as causes. It is acknowledged that sex hormones interfere with the host resistance to parasitic infections through a number of immunological interactions (Roberts et al. 1996). Thus, in mammalian parasite host systems testosterone has been found to depress the immune response of rats to intestinal nematodes (Tiuria et al. 1994). We have obtained some circumstantial evidence that the recorded G. derjavini population increase following testosterone injection is (at least partly) caused by an immunosuppressing effect of the male sex hormone. Part of this evidence is the dynamic variation of site selection on the host, a parameter which has been suggested to reflect the host response (Buchmann \& Bresciani 1997). Indeed, variations in the parasite site selection in the 2 rainbow trout groups indicate that some response mechanisms differ weakly between the 2 experimental groups. Thus, the possibility that testosterone injection interferes with the host response to gyrodactylids on the pectoral fins cannot be excluded. Changes in site selection of gyrodactylids on the hosts during a period of infection were previously noted by Harris (1988) and Cone \& Cusack (1989). Later findings of this phenomenon have been interpreted as being an escape of parasites from localized immune reactions in the skin (Richards \& Chubb 1996, Buchmann \& Bresciani 1997, Buchmann \& Uldal 1997).

Acquired immunity to infection was indeed clearly demonstrated in the donor fish used for the cohabitation in the present study. These trout, previously infected by a large number of parasites in the preceding $6 \mathrm{wk}$, were able to reduce the infection intensity to a low level despite the high infection pressures in the fish tanks. Similar reports of acquired immunity to monogenean infections in other teleosts have previously been presented by Jahn \& Kuhn (1932), Nigrelli \& Breder (1934), Paperna (1964), Molnar (1971), Vladimirov (1971), Lester (1972), Scott \& Robinson (1984), Slotved \& Buchmann (1993), Bondad-Reantaso et al. (1995) and Richards \& Chubb (1996). In addition, rainbow trout have previously been shown to respond to infections with Gyrodactylus salaris (Bakke et al. 1991) and with G. colemanensis (Cone \& Cusack 1989). In our experiment donor rainbow trout exhibited a marked host response and a large proportion of the parasites escaped from the pectoral fins to the immunologically safe corneal surface and tail fin, where mucous cells are absent or few (Buchmann \& Bresciani 1997). The body surface also carried a sub- 
stantial number of gyrodactylids but, due to the large surface area there, parasite density was low compared to the cornea, which has a very small surface area (Buchmann \& Bresciani 1997). The localization of monogeneans on the cornea of some fishes was mentioned by Jahn \& Kuhn (1932) and Nigrelli \& Breder (1934). This made Llewellyn (1957) (cited by Kearn 1976) suggest the lack of vascularization in the cornea as the causative factor for this predilection. In addition to this, Buchmann \& Uldal (1997) and Buchmann \& Bresciani (1997) presented evidence that the absence of mucous cells in the cornea could explain colonization of the cornea in the later stages of infection when the host immune system has been activated. The mucous cell density and the associated amount of immunologically active immune substances in these cells are likely to affect parasite localization. This is in accordance with studies on mammals in which intestinal goblet cells have been found to act as an important barrier against helminth infections (Ishikawa et al. 1994). Further, Wells \& Cone (1990) presented evidence that the mucous cell count decreases during an infection of rainbow trout with $G$. colemanensis. This indicates active involvement of these cells in the host response. Mucous cell density was therefore measured in the present study and it was actually found to differ between groups. Compared to uninfected fish both hormone-injected and placebo fish showed a marked decrease in cell density after infection. The testosterone-treated fish showed no significant lowering of cell density compared to placebo fish, but the highly responsive donor fish showed a clearly elevated count compared to both groups. There were indications that this elevation was caused by regeneration of cells. This bears resemblance to studies on intestinal goblet cells responding to intestinal parasites in the later stages of infection. In these cells at those stages alterations of the mucins are seen when worms are expelled (Ishikawa et al. 1994). As no differences in mucous cell counts were found between hormone-treated and untreated fish, this particular parameter did not indicate the presence of an immunosuppressive effect caused by testosterone (provided that rainbow trout mucous cell density reflects the host's ability to resist gyrodactylid infection).

Although some evidence has been presented to suggest that testosterone has an immunosuppressive effect in rainbow trout, other possible explanations of the observed population increase of Gyrodactylus derjavini should not be excluded. We have presented no evidence to reject the possibility that testosterone positively and directly enhances reproduction of the gyrodactylids. In addition, it should be noted that the 2 possibilities are not mutually exclusive. Classical studies have actually demonstrated that reproduction of monogeneans from the genera Polystoma and Diplozoon are affected by sex hormones from the host (see Smyth 1976) and such interactions are still possible in the rainbow trout/G. derjavini system.

Acknowledgements. This study was supported by the Danish Agricultural and Veterinary Research Council. The assistance of B. Østergaard in parasite counting is highly appreciated. The author is indebted to J. Bjerregaard, Department of Pharmacy, RVAU, who prepared the testosterone and placebo solutions.

\section{LITERATURE CITED}

Appleby C (1996) Population dynamics of Gyrodactylus sp. (Monogenea) infecting the sand goby in the Oslo Fjord, Norway. J Fish Biol 49:402-410

Appleby C, Mo TA (1996) Population dynamics of Gyrodactylus salaris (Monogenea) infecting Atlantic salmon parr Salmo salar, in the river Batnfjordselva, Norway. J Parasitol 83:23-30

Bakke TA, Jansen PA, Kennedy CR (1991) The host specificity of Gyrodactylus salaris Malmberg (Platyhelminthes, Monogenea): susceptibility of Oncorhynchus mykiss (Walbaumi under experimental conditions. J Fish Biol 39: $45-57$

Bondad-Reantaso MG, Ogawa K, Yoshinaga T, Wakabayashi $\mathrm{H}$ (1995) Acquired protection against Neobenedenia girellae in Japanese flounder. Fish Pathol 30:233-238

Buchmann K, Bresciani J (1997) Microenvironment of Gyrodactylus derjavini on rainbow trout Oncorhynchus mykiss: association between mucous cell density in skin and site selection. Parasitol Res (in press)

Buchmann K, Uidal A (1997) Gyrodactylus derjavini on four salmonids: comparative host susceptibility and site selection of parasites. Dis Aquat Org 28:201-209

Cone DK, Cusack R (1989) Infrapopulation dispersal of Gyrodactylus colemanensis (Monogenea) on fry of Salmo gairdneri. J Parasitol 75:702-706

Harris PD (1988) Changes in the site specificity of Gyrodactylus turnbulli Harris, 1986 (Monogenea) during infections of individual guppies (Poecilia reticulata Peters, 1859). Can J Zool 66:2854-2857

Ishikawa N, Horii Y, Oinuma T, Suganuma, Nawa Y (1994). Goblet cell mucins as the selective barrier for the intestinal helminths: T-cell-independent alteration of goblet cell mucins by immunologically 'damaged' Nippostrongylus brasiliensis worms and its significance on the challenge infections with homologous and heterologous parasites. Immunology 81:480-486

Jahn TL, Kuhn LR (1932) The life history of Epibdella melleni Maccallum 1927, a monogenetic trematode parasitic on marine fishes. Biol Bull (Woods Hole) 62:89-111

Kearn GC (1976) Body surface of fishes. In: Kennedy CR (ed) Ecological aspects of parasitology. North-Holland Publishing Company, Amsterdam, p 185-208

Lester RJG (1972) Attachment of Gyrodactylus to Gasterosteus and host response. J Parasitol 58:717-722

Malmberg G, Malmberg M (1993) Species of Gyrodactylus (Platyhelminthes, Monogenea) on salmonids in Sweden. Fish Res 17:59-68

Margolis L, Esch GW, Holmes JC, Kuris AM, Schad GA (1982) The use of ecological terms in parasitology. J Parasitol 68: 131-133

Molnar K (1971) Studies on gill parasitosis of the grasscarp 
(Ctenopharyngodon idella) caused by Dactylogyrus lamellatus Achmerow, 1952. II. Act Vet Acad Sci Hung 21. 361-375

Nigrelli RF, Breder CM (1934) The susceptibility and immunity of certain fishes to Epibdella melleni, a monogenetic trematode. J Parasitol 20:259-269

Paperna I (1964) Host reaction to infestation of carp with Dactylogyrus vastator Nybelin 1924 (Monogenea). Bamidgeh 16:129-141

Pickering AD (1977) Seasonal changes in the epidermis of the brown trout Salmo trutta (L.). J Fish Biol 10:561-566

Pickering AD, Christie P (1980) Sexual differences in the incidence and severity of ectoparasitic infestation of the brown trout, Salmo trutta L. J Fish Biol 16:669-683

Richards GR, Chubb JC (1996) Host response to initial and challenge infections, following treatment, of Gyrodactylus bullatarudis and $G$. turnbulli (Monogenea) on the guppy (Poecilia reticulata). Parasitol Res 82:242-247

Roberts CW, Satoskar A. Alexander J (1996) Sex steroids, pregnancy-associated hormones and immunity to parasitic infection. Parasitol Today 12:382-388

Responsible Subject Editor: Wolfgang Körting, Hannover, Germany
Scott ME, Robinson MA (1984) Challenge infections of Gyrodactylus bullatarudis (Monogenea) on guppies (Poecilia reticulata) following treatment. J Fish Biol 24:581-586

Slotved HC, Buchmann K (1993) Acquired resistance of the eel, Anguilla anguilla $\mathrm{L}$., to challenge infections with gill monogeneans. J Fish Dis 16:585-591

Smyth JD (1976) Introduction to animal parasitology, 2nd edn. Hodder \& Stoughton, London

Tiuria R, Horii Y, Tateyama S, Tsuchiya K, Nawa Y (1994) The indian soft-furred rat, Millardia meltada, a new host for Nippostrongylus brasiliensis, showing androgen-dependent sex difference in intestinal mucosal defence. Int $\mathrm{J}$ Parasitol 24:1055-1057

Vadimirov VL (1971) The immunity of fishes in the case of dactylogyrosis. Parasitologiya (Leningr) 5:51-58 (in Russian). English translation: Parasitology, Riverdale 1971, $1: 58-68$

Wells PR, Cone DK (1990) Experimental studies on the effect of Gyrodactylus colemanensis and G. salmonis on density of mucous cells in the epidermis of fry of Oncorhynchus mykiss. J Fish Biol 37:599--603

Manuscript received: March 5, 1997

Revised version accepted: May 26, 1997 